\title{
Different Alterations in the Insulin-stimulated Glucose Uptake in the Athlete's Heart and Skeletal Muscle
}

\author{
Pirjo Nuutila, * M. Juhani Knuuti, Olli J. Heinonen, * Ulla Ruotsalainen," Mika Teräs, "Jörgen Bergman," Olof Solin," \\ Hannele Yki-Järvinen," Liisa-Marja Voipio-Pulkki, " Uno Wegelius," and Veikko A. Koivisto" \\ Departments of ${ }^{*}$ Medicine and ${ }^{\ddagger}$ Clinical Chemistry, University of Turku, SF-20520 Turku, Finland; ${ }^{\S}$ Turku University Cyclotron/PET \\ Center, SF-20520 Turku, Finland; "Accelerator Laboratory, Abo Akademi, SF-20520 Turku, Finland; and \\ 'Second Department of Medicine, University of Helsinki, SF-00290 Helsinki, Finland.
}

\begin{abstract}
Physical training increases skeletal muscle insulin sensitivity. Since training also causes functional and structural changes in the myocardium, we compared glucose uptake rates in the heart and skeletal muscles of trained and untrained individuals. Seven male endurance athletes $\left(\mathrm{VO}_{2} \max 72 \pm 2 \mathrm{ml} / \mathrm{kg} / \mathrm{min}\right)$ and seven sedentary subjects matched for characteristics other than $\mathrm{VO}_{2} \max (43 \pm 2 \mathrm{ml} / \mathrm{kg} / \mathrm{min})$ were studied. Whole body glucose uptake was determined with a 2 -h euglycemic hyperinsulinemic clamp, and regional glucose uptake in femoral and arm muscles, and myocardium using ${ }^{18} \mathrm{~F}$-fluoro-2-deoxy-D-glucose and positron emission tomography. Glucose uptake in the athletes was increased by $68 \%$ in whole body $(P<0.0001)$, by 99\% in the femoral muscles $(P<0.01)$, and by $62 \%$ in arm muscles $(P=0.06)$, but it was decreased by $33 \%$ in the heart muscle $(P<0.05)$ as compared with the sedentary subjects. The total glucose uptake rate in the heart was similar in the athletes and control subjects. Left ventricular mass in the athletes was $79 \%$ greater $(P<0.001)$ and the meridional wall stress smaller $(P<0.001)$ as estimated by echocardiography. $\mathrm{VO}_{2}$ max correlated directly with left ventricular mass ( $r$ $=0.87, P<0.001)$ and inversely with left ventricular wall stress $(r=-0.86, P<0.001)$. Myocardial glucose uptake correlated directly with the rate-pressure product $(r=0.75, P$ $<0.02)$ and inversely with left ventricular mass $(r=-0.60, P$ $<0.05)$ or with the whole body glucose disposal $(r=-0.68, P$ $<0.01$ ). Thus, in athletes, $(a)$ insulin-stimulated glucose uptake is enhanced in the whole body and skeletal muscles, $(b)$ whereas myocardial glucose uptake per muscle mass is reduced possibly due to decreased wall stress and energy requirements or the use of alternative fuels, or both. (J. Clin. Invest. 1994. 2267-2274.) Key words: endurance training • heart • skeletal muscle $\bullet$ glucose uptake $\bullet$ positron emission tomography
\end{abstract}

\section{Introduction}

The heart can derive its energy from a variety of fuels such as fatty acids, glucose, lactate, and ketone bodies $(1,2)$. The heart preferentially uses substrates that yield energy by mitochondrial metabolism such as free fatty acids (FFA) and lactate,

Address correspondence to Dr. Pirjo Nuutila, M.D., Department of Medicine, University of Turku, SF-20520 Turku, Finland.

Received for publication 13 July 1993 and in revised form 17 November 1993.

J. Clin. Invest.

(C) The American Society for Clinical Investigation, Inc.

$0021-9738 / 94 / 05 / 2267 / 08 \$ 2.00$

Volume 93, May 1994, 2267-2274 while glycolysis normally produces only $\sim 30 \%$ of energy for the heart (3-7). However, the contribution of different fuels vary depending on the substrate availability, myocardial blood flow, oxygen supply, and energy needs of the heart. There is a shift from fatty acid to glucose utilization during acute stress such as tachycardia (8) and during a chronic increase in workload as in hypertensive individuals (9). During physical exercise which increases blood lactate concentrations, lactate becomes the most important source of energy for the heart (5). Endurance training increases myocardial workload and induces functional changes, such as an increase in stroke volume, maximal cardiac output and myocardial contractility during maximal exercise (10). In individuals doing isotonic exercise there is a rise in left ventricular end-diastolic volume, while isometric exercise thickens the left ventricular free wall and septum $(11,12)$.

While an increase in skeletal muscle insulin sensitivity in the athletes is well established $(13,14)$, it is not known whether the functional and structural changes of the athlete heart lead also to changes in fuel utilization under resting conditions. Animal studies have shown either no change (15) or an increase (16) in myocardial glucose uptake in response to physical training. In the absence of any change in total glucose uptake, regional differences in the myocardial glucose uptake are altered by training: while the majority of glucose is taken up by the subendocardial layer in sedentary animals, this transmural distribution of cardiac glucose uptake disappears by physical training (17). In skeletal muscle, physical training increases the total activity of mitochondrial enzymes involved in betaoxidation and respiratory chain. This is accounted for by the increase in the mitochondrial size and number (18). However, no changes occur in the heart mitochondrial size or enzyme activity (18). Since the enzymatic responses to physical training are different in the skeletal muscle and the heart, one would anticipate differences also in the metabolic adjustment of the skeletal muscle and myocardium. However, we are not aware of any studies addressing the influence of physical training on myocardial glucose uptake in man.

The use of positron emission tomography (PET) ${ }^{1}$ together with the administration of ${ }^{18} \mathrm{~F}$-fluoro-2-deoxy-D-glucose $\left({ }^{18} \mathrm{FDG}\right)$ has made it possible to quantitate noninvasively regional glucose uptake both in the heart and skeletal muscles in man (19-23). In the present study, we used this technique to quantitate the response of glucose uptake to insulin in the heart, arm, and leg muscle in endurance athletes and sedentary healthy subjects. Whole body glucose uptake was determined simultaneously using the euglycemic insulin clamp technique.

1. Abbreviations used in this paper: ${ }^{18} \mathrm{FDG},{ }^{18}$ fluoro-2-deoxy-D-glucose; LBM, lean body mass; PET, positron emission tomography; ROIs, regions of interest; $\mathrm{VO}_{2}$ max, maximal aerobic power. 


\section{Methods}

\section{Subjects}

Seven male endurance athletes (age $28 \pm 1 \mathrm{yr}$, weight $77 \pm 2 \mathrm{~kg}$, body mass index $22.0 \pm 0.4 \mathrm{~kg} / \mathrm{m}^{2}$ ) and seven age and weight matched sedentary healthy subjects (age $29 \pm 1 \mathrm{yr}$, weight $78 \pm 4 \mathrm{~kg}$, body mass index $23.2 \pm 0.8 \mathrm{~kg} / \mathrm{m}^{2}$ ) participated in the study. Six of the athletes had competed at world-class level (cross-country skiing, triathlon) and they had engaged in regular running exercise consisting of more than $10 \mathrm{~km}$ per day in 5-6 d per week for more than $5 \mathrm{yr}$ before the study. The control group did not exercise on a regular basis. The subjects were healthy as judged by history and physical examination and routine laboratory tests, and were not taking any medication. At least $3 \mathrm{~d}$ before the study, the subjects consumed a weight-maintaining diet containing $250-300 \mathrm{~g}$ carbohydrate, and at least one day before the study avoided to participate in any physical training. The nature, purpose, and potential risks of the study were explained to all subjects before they gave their voluntary consent to participate. The study was approved by the Ethical Committee of the Turku University Hospital.

\section{Study design}

The study consisted of a 120-min hyperinsulinemic period (Fig. 1). Between 0 and $120 \mathrm{~min}$, whole body glucose uptake was measured under euglycemic hyperinsulinemia using the insulin clamp technique. For the measurement of heart and skeletal muscle glucose uptake, ${ }^{18}$ FDG was injected at $60 \mathrm{~min}$, and dynamic scanning was started. Blood samples for the measurement of plasma glucose, blood lactate, serum insulin and FFA concentrations and ${ }^{18}$ FDG radioactivity were taken as detailed below.

\section{Whole body glucose uptake}

Whole body glucose uptake was determined using the euglycemic insulin clamp technique as previously described (22-24). All studies were performed starting at $8 \mathrm{a} . \mathrm{m}$. after a 10-12-h overnight fast. Two catheters were inserted, one in an antecubital vein for infusion of glucose and insulin, and injection of ${ }^{18} \mathrm{FDG}$, and one in a heated $\left(70^{\circ} \mathrm{C}\right)$ hand vein for sampling of arterialized venous blood.

At $0 \mathrm{~min}$, serum insulin was increased for $120 \mathrm{~min}$ using a primedcontinuous infusion of insulin (Actrapid, Novo Nordisk A/S, Copenhagen, Denmark). The rate of the continuous insulin infusion was 1 $\mathrm{mU}$ (or $7.2 \mathrm{pmol}$ ) $/ \mathrm{kg}$ per min. Normoglycemia was maintained using a variable rate infusion of $20 \%$ glucose. The rate of the glucose infusion was adjusted according to the plasma glucose concentration, which was measured from arterialized venous blood. Hepatic glucose production is completely suppressed under these conditions $(25,26)$. The rate of whole body glucose uptake was calculated during the time of PET scanning (60-120 min). Blood samples were taken at 5-10-min intervals for determination of blood glucose (27) and other samples at 2030 -min intervals for measurement of blood lactate (28), serum insulin (29), and FFA (30).

\section{Regional glucose uptake by heart and skeletal muscles}

These measurements were performed using positron emission tomography as previously described $(22,23)$. The method included the following procedures.

Preparation of ${ }^{18} \mathrm{FDG} .{ }^{18} \mathrm{FDG}$ was synthesized with an automatic apparatus essentially as described by Hamacher et al. (31). The specific radioactivity at the end of the synthesis was $\sim 2 \mathrm{Ci} / \mu \mathrm{mol}$ and the radiochemical purity exceeded $98 \%$.

Image acquisition. An eight-ring ECAT 931/08-tomograph (Siemens/CTI Corp., Knoxville, TN) was used. The device has a measured axial resolution of $6.7 \mathrm{~mm}$ and resolution of $6.5 \mathrm{~mm}$ in plane (32). The subject was positioned in the tomograph first with arms on sides so that the heart and the proximal one third of the upper extremities was within the gantry. Thereafter images were obtained from femoral regions. Before emission scanning, a transmission scan for correction of attenuation in the body was performed for $20-30 \mathrm{~min}$. In each plane $15-30 \times 10^{6}$ counts were obtained.

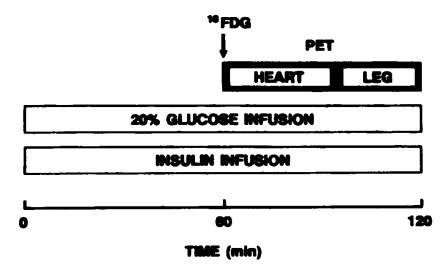

$1 \mathrm{~h}$ after starting the insulin infusion, $7-8 \mathrm{mCi}$ of ${ }^{18} \mathrm{FDG}$ was injected intravenously over 10-20 s (Fig. 1). Dynamic scanning of the thoracic region was started simultaneously and continued for $\mathbf{4 0} \mathrm{min}$ $(8 \times 15 \mathrm{~s}, 2 \times 30 \mathrm{~s}, 2 \times 120 \mathrm{~s}, 1 \times 180 \mathrm{~s}, 6 \times 300 \mathrm{~s})$. Thereafter, five dynamic scans of $300 \mathrm{~s}$ each were taken from the femoral region. Blood samples for measurement of plasma radioactivity were drawn during dynamic scanning. Radioactivity was measured with a well counter and the value was converted to PET counts using a calibration factor derived from phantom studies.

Image processing. All data were corrected for deadtime, decay, and measured photon attenuation as previously described $(22,23)$ and reconstructed into a $256 \times 256$ matrix. For determination of heart glucose uptake, elliptical regions of interest (ROIs) were placed on four or more mid-ventricular slices. The total number of ROIs was 25-30 (septum, free wall, apex) and they were 40-110 pixels/ROI in size. All myocardial time-activity curves were corrected for partial-volume effect and spill-over effect from cavity (33). In the skeletal muscle, ROIs were outlined in four slices on the anterior and posterior muscular compartments in the arm opposite to the injection site of ${ }^{18} \mathrm{FDG}$. In the legs we used posterior, anterolateral, and anteromedial muscular compartments of the femoral region (four slices in both legs). Their localization was verified by comparison with the position in the transmission images. The number of pixels per ROI in the arm was $80-120$, and in the femoral region 140-360.

Calculation of regional glucose uptake. The three compartment model of ${ }^{18} \mathrm{FDG}$ kinetics was employed as described previously $(22,23$, 34,35 ). Plasma and tissue time-activity curves were analyzed graphically to quantitate the fractional rate of tracer phosphorylation $K_{\mathrm{i}}(20)$.

$K_{\mathrm{i}}=\left(k_{1} \times k_{3} / k_{2}+k_{3}\right)$

where $k_{1}$ is the transfer coefficient from vascular space into the tissue, $k_{2}$ is the initial clearance and efflux coefficient, and $k_{3}$ is the phosphorylation rate constant. In this study, the whole fitted plasma time-activity curve was used as the input function and a minimum of ten time points were used to determine the slope by linear regression for the thoracic study and a minimum of five points were used for femoral study. The plots between the points were linear (for myocardium $r=0.97 \pm 0.02$, for skeletal muscle $r=0.90 \pm 0.04$ ) and the residuals of the regression lines were stocastically scattered.

The rate of the glucose uptake is obtained by multiplying $\mathrm{K}_{\mathrm{i}}$ by the plasma glucose concentration $[\mathrm{Glc}]_{\mathrm{p}}$ divided by a lumped constant term (LC):

$r G U=\left([G l c]_{\mathrm{p}} / L C\right) \times K_{\mathrm{i}}$

(ref 19)

The lumped constant accounts for differences in the transport and phosphorylation of ${ }^{18} \mathrm{FDG}$ and glucose. Lumped constant values, 0.67 for the heart $(22,23,36,37)$ and 1.0 for the skeletal muscle $(22,23,38)$ were used as previously described.

The rate of regional glucose uptake (leg, arm, heart) was expressed per muscle mass ( $\mu \mathrm{mol} / \mathrm{kg}$ muscle per min; see Fig. 2, lower panel). We also wished to estimate the amount of glucose taken up by all muscles in the body and the heart (see Fig. 2, upper panel). The estimation was done from the PET measurements of muscle glucose uptake in the femoral, arm and the heart regions, and the estimations of the skeletal muscle content and left ventricle mass of the subjects. The rate 
of total muscle glucose uptake was calculated by multiplying the regional muscle glucose uptake, as determined directly in muscle compartments with PET ( $\mu \mathrm{mol} / \mathrm{kg}$ muscle per $\min )$, by the total amount of muscle.

Body fat and muscle content. Body fat and muscle content was estimated from four skinfolds ( subscapular, triceps brachii, biceps brachii, and crista iliaca) as measured with a calliper (39). The values of the four skinfolds were summed up and divided by body weight to obtain skinfold/body weight ratio ( $R$ ). Percentage of fat was calculated as follows:

percent fat $=11.5453 \times R-0.2838$

As shown in our previous study, body muscle percentage per lean body mass was $43 \%$ both for runners and sedentary control subjects (40).

Left ventricular structure. M-mode and two-dimensional echocardiography (Acuson $128 \mathrm{XP} / 5$, Acuson Inc, CA) were performed in the athletes and control subjects to determine end-diastolic and end-systolic left ventricular dimensions, and septal and posterior free-wall thicknesses. Left ventricular mass was calculated according to ASE method (41). Meridional left ventricular wall stress was estimated according to equation:

$W S=(p \cdot r) /\left[2 W_{\mathrm{th}} \cdot\left(1+W_{\mathrm{th}} / 2 r\right)\right]$

in which $W S$ is wall stress, $p$ is systolic blood pressure, $r$ is systolic internal radius of left ventricle, and $W_{\text {th }}$ is wall systolic thickness (42).

Maximal aerobic power. Maximal aerobic power $\left(\mathrm{VO}_{2} \max \right)$ was determined in all athletes and six control subjects using electrically braked cycle ergometer (model $800 \mathrm{~S}$; Ergoline, Mijnhardt, Netherlands) with a continuous incremental protocol. Direct respiratory measurements were made using an automated system (model 202; Medikro, Kuopio, Finland). Subjects breathed through Daniel's valve, with expired gases directed to a mixing chamber for paramagnetic $\mathrm{O}_{2}$ and infrared $\mathrm{CO}_{2}$ analysis (Datex Division, Instrumentarium Corporation, Helsinki, Finland). Outputs from these instruments were directed to a laboratory computer for calculation of ventilation, $\mathrm{O}_{2}$ consumption $\left(\mathrm{VO}_{2}\right), \mathrm{CO}_{2}$ production $\left(\mathrm{VCO}_{2}\right)$, and respiratory exchange ratio $(\mathrm{R})$ every $30 \mathrm{~s}$. The $\mathrm{VO}_{2}$ max test consisted of a short warm-up, after which the load was increased from $100 \mathrm{~W}$ by $30 \mathrm{~W}$ (sedentary) or from $200 \mathrm{~W}$ by $25 \mathrm{~W}$ (athletes) every 2 min until exhaustion. The criteria used to establish the $\mathrm{VO}_{2}$ max were a plateau in $\mathrm{VO}_{2}$ with increasing exercise intensity and $\mathrm{R}>1.10$. Calibration against standard gases $\left(16 \% \mathrm{O}_{2}\right.$ and $\left.4 \% \mathrm{CO}_{2}\right)$, volume $(3,000 \mathrm{ml})$, room temperature and barometric pressure was performed before and immediately after each test.

\section{Statistical procedures}

Statistical comparisons between athletes and controls were performed using the unpaired $t$ test and correlations were calculated using Pearson's or Spearman's correlation analysis and multiple linear regression analysis where appropriate (43). Analysis of covariance was used to study the influence of wall stress to glucose uptake rates in the heart.

\section{Results}

Subject characteristics. Maximal aerobic power in the athletes $(72 \pm 2 \mathrm{ml} / \mathrm{kg} / \mathrm{min}$ ) was $67 \%$ higher than in the sedentary control subjects $(43 \pm 2 \mathrm{ml} / \mathrm{kg} / \mathrm{min}, P<0.001)$. The percentage $(8.6 \pm 0.6$ vs $15.2 \pm 1.3 \%, P<0.001)$ and total amount of fat $(6.6 \pm 0.3 \mathrm{~kg}$ vs $12.1 \pm 1.5 \mathrm{~kg}, P<0.01)$ was smaller in the athletes than in the sedentary subjects, whereas the total muscle content was similar in the two groups $(29.3 \pm 0.8 \mathrm{~kg}$ vs $27.8 \pm 1.6$ $\mathrm{kg}$ ), respectively.

In the athletes, the left ventricular diastolic volume (121 \pm 3 $\left.\mathrm{cm}^{3} / \mathrm{m}^{2}\right)$ and left ventricular mass $\left(127 \pm 4 \mathrm{~g} / \mathrm{m}^{2}\right)$ were 78 and $79 \%$ greater than the respective values in the control subjects $\left(68 \pm 6 \mathrm{~cm}^{3} / \mathrm{m}^{2}\right.$, and $71 \pm 7 \mathrm{~g} / \mathrm{m}^{2}, P<0.001$ for both $)$. There was no overlapping in the left ventricular volume or the left ventricular mass between the two groups. In the athletes both the left ventricular wall $(11 \pm 1 \mathrm{~mm})$ and septum $(11 \pm 1 \mathrm{~mm})$ were thicker than in the control subjects $(8 \pm 1 \mathrm{~mm}, P<0.001$, and $8 \pm 1 \mathrm{~mm}, P<0.01$, respectively). Left ventricular meridional wall stress was smaller in the athletes $(6.7 \pm 0.2 \mathrm{kPa} /$ $\mathrm{cm}^{2}$ ) than in the control subjects $\left(9.8 \pm 0.5 \mathrm{kPa} / \mathrm{cm}^{2}, P\right.$ $<0.001)$. As determined during the insulin infusion, both blood pressure $(126 \pm 3 / 78 \pm 5 \mathrm{mmHg}$ vs $120 \pm 6$ vs $77 \pm 3$ $\mathrm{mmHg})$ and heart rate $(62 \pm 3 / \mathrm{min}$ vs $66 \pm 3 / \mathrm{min})$ were similar in the athletes and control subjects, respectively. Thus, the ratepressure products during the insulin clamp were similar in the two groups $(7830 \pm 380$ vs $6940 \pm 1460$ beats $/ \mathrm{min} \times \mathrm{mmHg}$, respectively). The rate-pressure product correlated with myocardial glucose uptake $(r=0.75, P<0.02)$. $\mathrm{VO}_{2} \max$ correlated directly with left ventricular mass $(r=0.87, P<0.001)$ and inversely with left ventricular wall stress $(r=-0.86, P$ $<0.001$ ).

Substrate and insulin concentrations. Plasma glucose concentrations both in the basal state $(5.0 \pm 0.1 \mathrm{mM}$ vs $4.9 \pm 0.2$ $\mathrm{mM})$ and during the insulin infusion $(4.8 \pm 0.1 \mathrm{mM}$ vs $5.0 \pm 0.1$ $\mathrm{mM}$ ) were similar in the athletes and control subjects. The fasting serum insulin concentration in the athletes $(35 \pm 7 \mathrm{pM})$ was lower than in the controls $(58 \pm 6 \mathrm{pM}, P<0.001)$, whereas during the time when ${ }^{18} \mathrm{FDG}$ uptake measurements were made (60-120 $\mathrm{min}$ ), insulin concentrations were similar in the two groups $(485 \pm 52 \mathrm{pM}$ vs $530 \pm 33 \mathrm{pM}$, respectively). Fasting blood lactate concentrations were similar in athletes and sedentary subjects $(1.12 \pm 0.08$ vs $0.95 \pm 0.11 \mathrm{mM}$, respectively). During the insulin infusion, blood lactate concentration increased in both groups $(P<0.05)$ and at the end of the study it was higher in the athletes $(1.60 \pm 0.06 \mathrm{mM})$ than in the sedentary subjects $(1.29 \pm 0.11 \mathrm{mM}, P<0.05)$. Serum fasting FFA concentrations were not significantly different between the athletes and control subjects, respectively ( $392 \pm 43 \mu \mathrm{M}$ vs $559 \pm 76$ $\mu \mathrm{M})$, and they were virtually identical at the end of the insulin infusion ( $84 \pm 9 \mu \mathrm{M}$ vs $88 \pm 13 \mu \mathrm{M})$.

Whole body, skeletal muscle, and heart glucose uptake. Whole body glucose uptake was $74 \%$ greater in the athletes as compared to control subjects $(4893 \pm 315$ vs $2818 \pm 226 \mu \mathrm{mol} /$ min, $P<0.001$, Fig. 2, upper panel). When expressed per lean body mass ( LBM), glucose uptake in the athletes was increased by $68 \%$ ( $70 \pm 4$ vs $42 \pm 3 \mu \mathrm{mol} / \mathrm{kgLBM} / \mathrm{min}, P<0.0001$, Fig. 2 , lower panel). The rate of whole body glucose disposal correlated with the blood lactate concentration during hyperinsulinemia, $r=0.79, P<0.01$.

When individual PET derived images of ${ }^{18}$ FDG uptake rates were scaled to the same counts/pixel level, in the athletes ${ }^{18}$ FDG uptake was increased in femoral muscles but decreased in the heart (Fig. 3). Compared with the sedentary subjects, glucose uptake in the athletes was $99 \%$ greater in the femoral muscles ( $168 \pm 23$ vs. $84 \pm 10 \mu \mathrm{mol} / \mathrm{kg}$ muscle $/ \mathrm{min}, P<0.01$ ) and $62 \%$ greater in the arm muscles ( $130 \pm 17 \mathrm{vs} .81 \pm 16 \mu \mathrm{mol} /$ $\mathrm{kg}$ muscle $/ \mathrm{min}, P=0.06)$. In the athletes the rate of glucose uptake in the femoral muscles was $29 \%$ greater than in the arm muscles $(P<0.02)$, but this difference was not observed in the sedentary subjects.

Myocardial glucose uptake was $33 \%$ lower in the athletes than in the sedentary subjects ( $562 \pm 65$ vs. $843 \pm 91 \mu \mathrm{mol} / \mathrm{kg}$ muscle $/ \mathrm{min}, P<0.05$, Fig. 2 , lower panel). In the athletes glucose uptake in the heart per muscle weight was $3.7 \pm 0.5$-fold greater than in femoral muscle, and this ratio was much lower 

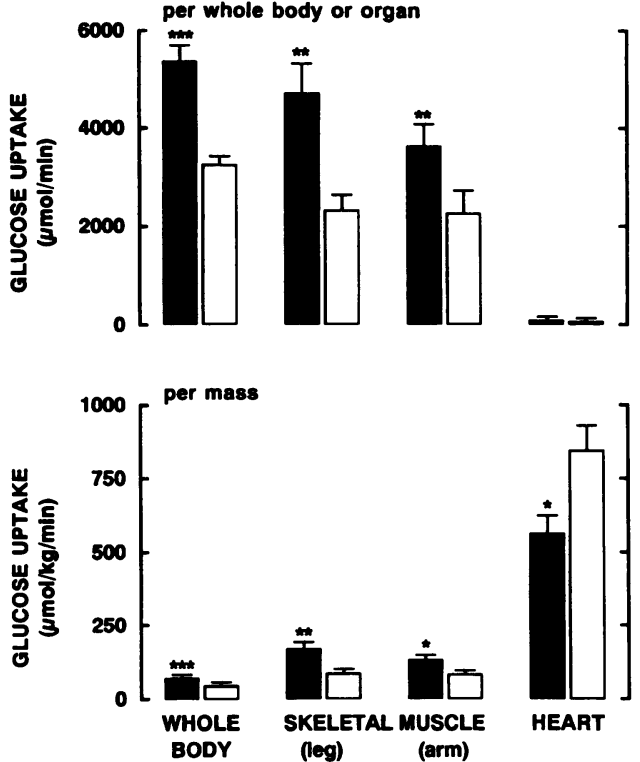

Figure 2. The rate of glucose uptake in the whole body, leg, arm, and heart muscles. The values in the lower panel are expressed per $\mathrm{kg}$ LBM for the whole body as determined with insulin clamp, and per kg muscle for the skeletal or heart muscle as measured with PET. The upper panel represents the rates of glucose uptake for the whole body, all the skeletal muscles and the whole heart. These results are calculated from insulin clamp (whole body) or from PET results (femoral or arm muscles and the heart). Solid bars denote athletes and open bars sedentary control subjects. ${ }^{*} P<0.05,{ }^{* *} P<0.01$, $* * * P<0.001$ between athletes and sedentary subjects.

than in the control subjects $(10.6 \pm 1.4 P<0.001)$. Due to a larger heart muscle mass in the athletes, total glucose uptake by the heart was similar in the athletes and controls ( $145 \pm 13$ vs $136 \pm 20 \mu \mathrm{mol} / \mathrm{min}, 73 \pm 7$ vs $66 \pm 8 \mu \mathrm{mol} / \mathrm{m}^{2} / \mathrm{min}$, respectively, Fig. 2, upper panel).

Correlations between glucose uptake rates and $\mathrm{VO}_{2} \max$. There was a close positive correlation between the whole body and leg $(r=0.87, P<0.001)$ or arm glucose uptake $(r=0.81, P$ $<0.001)$, and between rates of arm and femoral muscle glucose uptake $(r=0.81, P<0.001)$. In contrast, whole body and heart glucose disposal were inversely related $(r=-0.68, P$ $<0.01$, Fig. $4, A-C)$.

Correlations between glucose uptake, echocardiographic findings, and FFA and lactate concentrations. There was an inverse correlation between heart glucose uptake per muscle weight and left ventricular mass $(r=-0.60, P<0.05)$. Heart glucose uptake per volume unit correlated with left ventricular wall stress $(r=0.58, P=0.06)$. When left ventricular wall stress was used as a covariate, glucose uptake per total heart muscle in the athletes and controls was similar. Using multiple linear regression analysis in the whole group, there was a significant inverse correlation between heart glucose uptake, and the mean FFA (0-120 min) and the blood lactate concentration at the end of insulin infusion $(r=-0.63, P<0.05)$.

\section{Discussion}

In the current study we determined glucose uptake rates in athletes and sedentary subjects in the whole body, in the skeletal muscles of leg and arm, and in the heart. Whole body glu- cose disposal was determined using euglycemic insulin clamp, and the uptake by the various muscle groups was measured with positron emission tomography after the injection of ${ }^{18}$ FDG. In keeping with the previous observations, whole body glucose disposal was greater in the athletes than sedentary subjects and proportional to the maximal aerobic power $(13,14$, 44). In contrast, myocardial glucose uptake per muscle volume unit was lower in the athletes than in untrained subjects and inversely related to both $\mathrm{VO}_{2}$ max and whole body insulin sensitivity. When expressed per total heart, however, heart glucose uptake rates were similar in both groups.

Decreased fasting insulin concentrations in the athletes in the present study were suggestive of increased insulin sensitivity and this was confirmed by the $74 \%$ greater whole body glucose disposal as determined with the insulin clamp technique. Although we did not measure residual hepatic glucose production during hyperinsulinemia, it was probably close to zero since, with insulin concentrations similar to those in this study, we have previously demonstrated a complete suppression in hepatic glucose production (26). Our results provide direct evidence that increased insulin sensitivity in the athletes was due to augmented skeletal muscle glucose disposal: in the femoral muscles it was increased by $99 \%$ and in the arm muscles by $62 \%$. A strenous bout of acute exercise may enhance insulin sensitivity for more than $24 \mathrm{~h}$ (45). Our subjects had no such exercise before the study. Thus, the observed increase in insulin sensitivity was due to chronic aerobic training rather than a consequence of acute exercise. Regarding the qualitative changes in muscle tissue leading to enhanced insulin sensitivity, factors such as enhanced capillary density (46), increased glycogen synthase activity $(47,48)$, increased mitochondrial volume and activity of oxidative enzymes (18) have been suggested to be involved. In the current study, we did not take muscle biopsies to examine possible differences in the muscle fiber composition or capillary density. However, in our recent study we demonstrated in the skeletal muscle of the athletes normal capillary density but increased blood flow and glucose transport protein (GLUT-4) concentrations, which can explain enhanced insulin sensitivity (48).

Myocardial glucose disposal rate per muscle volume unit was decreased by $33 \%$ in the athletes and correlated directly with myocardial work load as estimated with the rate-pressure product and inversely with whole body insulin sensitivity and left ventricular mass. Regarding the mechanisms of decreased glucose uptake by the athlete heart, possible effects of previous acute exercise, myocardial energy stores, utilization of alternative substrates, and heart work load should be considered. In experimental normo- or hypertensive animals, acute vigorous exercise decreases myocardial glucose uptake by 64 and 33\%, respectively, as determined immediately after exercise (49). The duration of the acute effect of exercise on myocardial glucose uptake is not known. Our subjects had not done any exercise for more than $24 \mathrm{~h}$ before the study. Thus, although the contribution of acute exercise can not totally be excluded, a reduced glucose uptake by the athlete's heart is more likely a consequence of regular training rather than acute exercise. In skeletal muscle, glucose disposal is increased in the presence of glycogen depletion (45). We were not able to measure myocardial glycogen content in the present study. In experimental animals physical training does not alter heart glycogen $(50)$ or water content (18). If the same is true in man, changes in myocardial glycogen content in the athlete's heart were not 

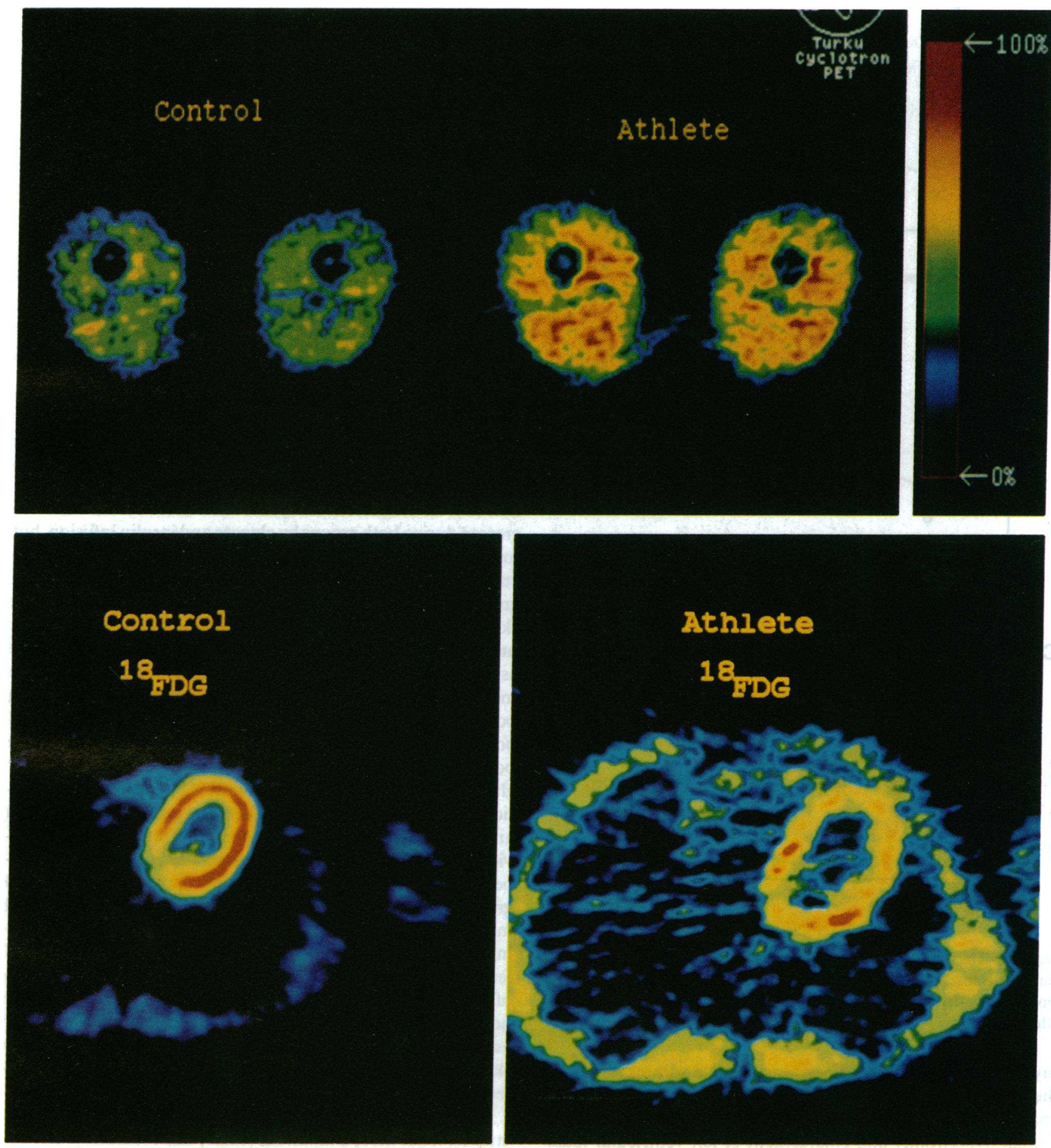

Figure 3. Examples of ${ }^{18}$ FDG images as determined with positron emission tomography of an athlete and a control subject scaled to the same counts per pixel level. Femoral region in the upper panel and thoracic region in the lower panel.

responsible for the decreased glucose uptake. Wall stress was smaller in the athletes than control subjects, suggesting also a decreased need of energy per contractile unit. Since glucose uptake by PET is determined per volume of the heart muscle, reduced glucose uptake may reflect decreased need of energy per the volume of heart muscle. The left ventricular mass was substantially increased in the athletes as previously described $(51,52)$, and it was increased in proportion to the physical fitness. Due to differences in heart size, total myocardial glucose uptake was similar in the two groups. In addition, the rate-pressure products were similar during the insulin clamp in the athletes and controls suggesting a similar work load for the whole heart. Thus, when the whole heart is taken into consideration, there was no difference in the external work or glucose uptake. These data suggest that myocardial hypertrophy associated with endurance training contributed to the reduced 

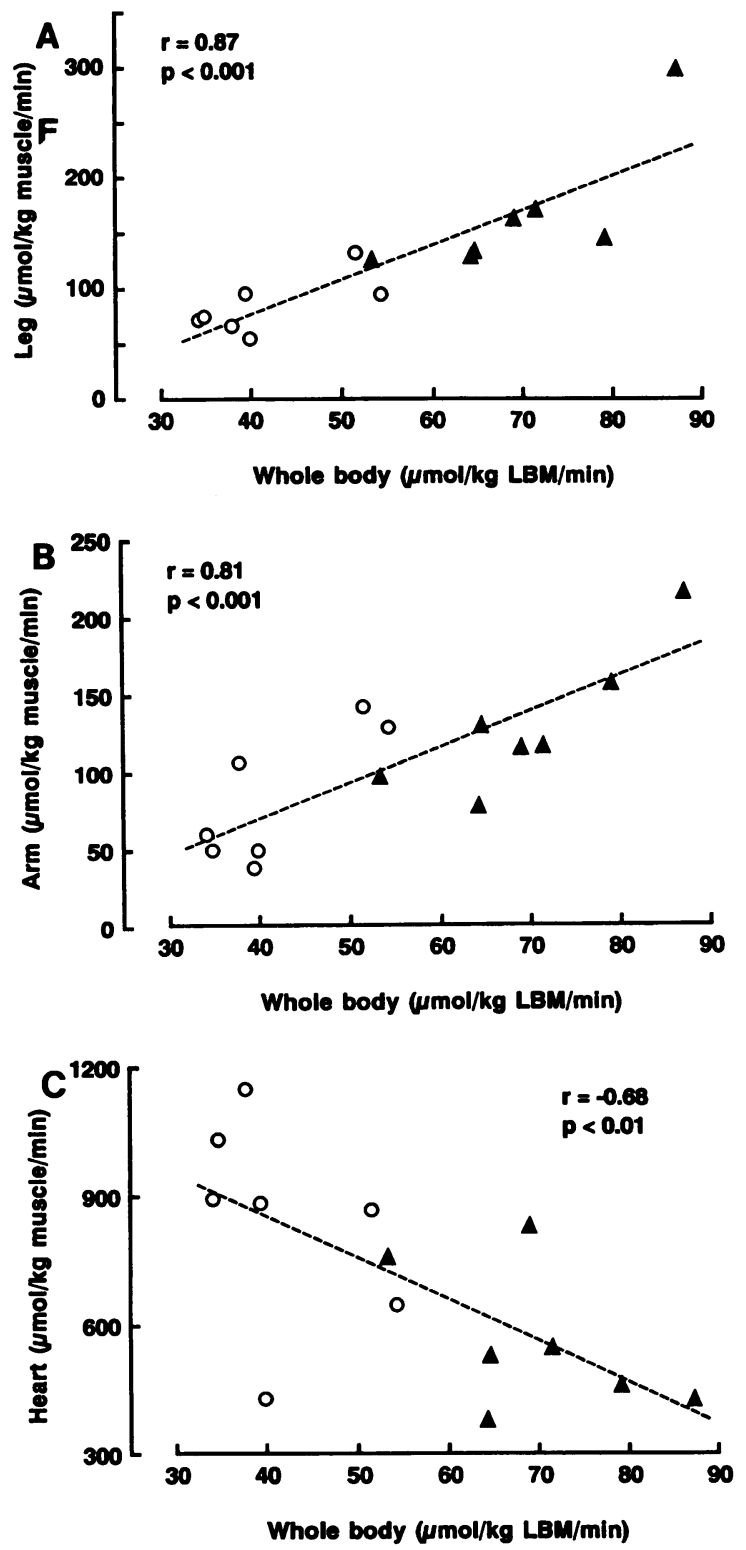

Figure 4. The correlation between whole body glucose uptake and glucose disposal by the femoral muscles $(A), \operatorname{arm}(B)$, or heart $(C)$. Open circles denote sedentary control subjects and solid triangles athletes.

myocardial glucose uptake per heart muscle volume at rest in the athletes. Regarding the course of structural and metabolic changes in the athlete heart, endurance training leads to myocardial hypertrophy and enlargement of left ventricular mass via wall thickening. The thickening of the wall reduces wall stress and thus the external work per contractile unit. In concert with the reduction of external work, also glucose uptake per contractile unit decreases. This hypothesis is supported by a correlation of borderline significance $(P=0.06)$ between wall stress and heart glucose uptake.

Regarding alternative fuels, circulating FFA are the major determinants of myocardial glucose uptake under a variety of circumstances. Three decades ago Randle and co-workers demonstrated in the isolated rat heart that both glucose uptake and oxidation are inhibited by high FFA concentrations (53). By increasing serum FFA concentrations in man with the infusion of Intralipid and heparin, we have recently demonstrated with PET a 30\% fall in myocardial glucose uptake under hyperinsulinemic conditions (22). In studies using normo-and hyperglycemic insulin clamp technique over a wide range of serum FFA concentrations, Wisneski et al. (6) demonstrated a close inverse relationship between heart glucose uptake and arterial FFA concentration in healthy man. We have recently demonstrated that physiologic changes in serum FFA concentrations can cause even fivefold alterations in myocardial glucose uptake in the face of unaltered insulin concentrations (54). Although serum FFA concentration in the athletes was not elevated, a possibility remains that they are more prone than sedentary subjects to partly substitute free fatty acids for glucose as an alternative fuel for the heart. Since we did not measure FFA kinetics, this hypothesis remains unproven.

A third major substrate for myocardium is lactate. Already four decades ago Bing et al. (3) demonstrated an increase in myocardial lactate extraction in response to a rise in arterial lactate concentration. More recently, studies in healthy men have shown that the contribution of lactate oxidation to myocardial ATP production is $\sim 13 \%$ in the fasting state. This is doubled with a twofold elevation of blood lactate concentration (6). In the current study, blood lactate concentration increased during both groups by glucose and insulin infusion, but to a higher level in the athletes than control subjects. The difference in blood lactate concentration can be accounted for by a greater rate of glucose utilization and lactate production by the skeletal muscle of the athletes (45). Blood lactate can contribute as a fuel for myocardium via two mechanisms. First, lactate as such is used as an alternative fuel for glucose. Second, lactate may facilitate the turnover of triacylglycerols by enhancing both FFA uptake and incorporation into the triacylglycerol pool, and FFA release as a fuel for myocardium $(55,56)$. The possibility of alternative fuels (FFA, lactate) substitution for glucose in the current study is supported by the inverse association in the multivariate analysis between heart glucose disposal and circulating FFA and lactate concentrations. In our previous studies both in healthy subjects (22) and in type 1 diabetic patients (23), we observed an approximately 10 -fold greater glucose uptake in the heart as compared to femoral muscles. Our current data in the sedentary subjects are in keeping with the earlier observations. However, due to increased femoral and a decreased myocardial glucose uptake, the ratio of heart/leg glucose uptake in the athletes was only 3.7. The nearly threefold greater ratio in the sedentary subjects further emphasizes the magnitude of the different adaptations in the skeletal muscle and heart glucose uptake in the endurance athletes.

Regarding the use of ${ }^{18} \mathrm{FDG}$ as a tracer in the glucose uptake studies, it has more similarities (mass, electronaffinity, and hydrogen bond acceptance of $\mathrm{F}^{-}$and $\mathrm{OH}^{-}$) with cold glucose than tritiated 2-deoxyglucose has. The lumped constant, adjusting for differences between the tracer and tracee, has varied from 0.8 to 1.2 for tritiated 2-deoxyglucose in skeletal muscle (57-59). Consequently, the lumped constant for $2-\left[{ }^{18} \mathrm{~F}\right]-\mathrm{FDG}$ in skeletal muscle should be closer to unity than that of 2-DG (38). As a lumped constant of ${ }^{18}$ FDG for the heart, 0.67 is commonly used $(36,37)$. For these reasons in our current and previous studies $(22,23)$ we assumed the lumped constant of ${ }^{18} \mathrm{FDG}$ to be 1.0 in the skeletal muscle, and 0.67 for the heart.

The design of our study was cross-sectional. Therefore it is not possible to estimate, whether the differences in the skeletal 
muscle and heart glucose uptake are entirely due to the effects of physical training, or whether a genetic endowment also contributes to these differences (60). Our athletes, who were involved in running exercise had greater glucose uptake rates in the leg than in the arm. In sedentary subjects this difference did not exist. However, even in the arms the athletes had glucose disposal greater than in the control subjects. It is possible that at least part of the augmented glucose uptake in the untrained arm muscles reflects genetic endowment rather than the effect of physical training, although systemic effects of training can not be excluded (60).

Taken together, our data suggest two possible mechanisms for reduced glucose uptake by the athlete heart as determined with PET. First, it is related to myocardial hypertrophy and reduced wall stress. In the face of comparable work loads as judged from the rate-pressure products, energy requirement may be lower in the athletic heart per myocardial mass. A possibility of differences in myocardial energy stores between athletes and sedentary subjects is neither excluded. Second, alternative fuels such as FFA or lactate may be used more by the athlete heart than the myocardium of the sedentary subjects. A third possibility is the contribution of both these mechanisms.

\section{Acknowledgments}

Our thanks go to the technicians in Turku University Cyclotron/PET Center for their skill and dedication throughout this study. We also thank Jukka Kapanen, M. Sci, and the Paavo Nurmi Center for $\mathrm{VO}_{2}$ max determinations.

This study was supported by grants from the Finnish Academy of Science, Nordisk Insulinfonds Komite, Orion Corporation Research Foundation, Diabetes Research Foundation, Turku University Foundation, and Arvo and Inkeri Suominen Foundation.

\section{References}

1. Taegtmeyer, H. 1988. Principles of fuel metabolism in heart muscle. In Myocardial Energy Metabolism. J. W. DeJong, editor. Martinus Nijhoff Publishers. Dordrecht, The Netherlands. 17-34.

2. Opie, L. H. 1991. Fuels: carbohydrates and lipids. In The Heart, Physiology and Metabolism. Raven Press, New York. 208-246.

3. Bing, R. J., A. Siegel, A. Vitale, F. Balboni, E. Sparks, M. Taeschler, M Klapper, and S. Edwards. 1953. Metabolic studies on the human heart in vivo. Am. J. Med. 15:284-296.

4. Neely, J. R., and H. E. Morgan. 1974. Relationship between carbohydrate and lipid metabolism and the energy balance of heart muscle. Annu. Rev. Physiol. 36:413-459.

5. Heiss, H. W., J. Barmeyer, J. Keul, and H. Reindell. 1977. Myocardial oxygen consumption and substrate uptake in man during physiological and pathological volume load. Basic Res. Cardiol. 72:293.

6. Wisneski, J. A., W. C. Stanley, R. A. Neese, and E. W. Gertz. 1990. Effects of acute hyperglycemia on myocardial glycolytic activity in humans. J. Clin. Invest. 85:1648-1656.

7. Lopaschuk, G. D., R. L. Collins-Nakai, and T. Itoi. 1992. Developmental changes in energy substrate use by the heart. Cardiovasc. Res. 26:1172-1180.

8. Camici, P., P. Marraccini, M. Marzilli, R. Lorenzoni, G. Buzzigoli, R Puntoni, C. Boni, C. R. Bellina, G. A. Klassen, A. L'Abbate, and E. Ferrannini. 1989. Coronary hemodynamics and myocardial metabolism during and after pacing in normal humans. Am. J. Physiol. 257:E309-E317.

9. Yonekura, Y., A. B. Brill, P. Som, K. Yamamoto, S. C. Srivastava, J. Iwai, D. R. Elmaleh, E. Livini, H. W. Strauss, M. M. Goodman, and F. F. Knapp, Jr. 1985. Regional myocardial substrate uptake in hypertensive rats: a quantitative autoradiographic measurement. Science (Wash. DC). 227:1494-1496.

10. Blomquist, C. G., and B. Saltin. 1983. Cardiovascular adaptations to physical training. Annu. Rev. Physiol. 45:169-189.

11. Huston, T. P., J. C. Puffer, and W. M. MacMillan Rodney. 1985. The athletic syndrome. N. Engl. J. Med. 313:24-32.

12. Maron, B. J. 1986. Structural features of the athlete heart as defined by echocardiography. J. Am. Coll. Cardiol. 7:190-203.
13. Lohman, D., F. Liebold, W. Heilmann, H. Senger, and A. Pohl. 1978. Diminished insulin response in highly trained athletes. Metabolism. 27:521-524.

14. Koivisto, V. A., H. Yki-Järvinen, and R. A. DeFronzo. 1986. Physical training and insulin sensitivity. Diabetes Metab. Rev. 1:445-481.

15. Kainulainen, H., T. E. S. Takala, I. E. Hassinen, and V. Vihko. 1985. Redistribution of glucose uptake by chronic exercise, measured in isolated perfused rat hearts. Pflugers Arch. Eur. J. Physiol. 403:296-300.

16. Kainulainen, H., P. Virtanen, H. Ruskoaho, and T. E. S. Takala. 1989. Training increases cardiac glucose uptake during rest and exercise in rats. Am. J. Physiol. 257:H839-H845.

17. Takala, T. E. S., H. J. Ruskoaho, and I. E. Hassinen. 1983. Transmural distribution of cardiac glucose uptake in rat during physical exercise. Am. J. Physiol. 244:H131-H137.

18. Oscai, L. B., P. A. Mole, B. Brei, and J. O. Holloszy. 1971. Cardiac growth and respiratory enzyme levels in male rats subjected to running program. $A m$. J Physiol. 220:1235-1241.

19. Sokoloff, L., M. Reivich, C. Kennedy, M. C. Des Rosiers, C. S. Patlak, K. D. Pettigrew, O. Sakurada, and M. Shinohara. 1977. The $\left[{ }^{14} \mathrm{C}\right]$ Deoxyglucose method for the measurement of local cerebral glucose utilization: theory, procedure and normal values in the conscious and anesthetized albino rats. J. Neurochem. 28:897-916.

20. Patlak, C. S., and R. G. Blasberg. 1985. Graphical evaluation of blood-tobrain transfer constants from multiple-time uptake data. Generalizations. $J$ Cereb. Blood Flow Metab. 5:584-590.

21. Gambhir, S. S., M. Schwaiger, S.-C. Huang, J. Krivokapich, H. R. Schelbert, C. A. Nienaber, and M. Phelps. 1989. A simple non-invasive quantification method for measuring myocardial glucose utilization in humans employing positron emission tomography and ${ }^{18} \mathrm{~F}$-deoxyglucose. J. Nucl. Med. 30:359-366.

22. Nuutila, P., V. A. Koivisto, J. Knuuti, U. Ruotsalainen, M. Teräs, M. Haaparanta, J. Bergman, O. Solin, L.-M. Voipio-Pulkki, U. Wegelius, and H. Yki-Järvinen. 1992. The glucose-free fatty acid cycle operates in human heart and skeletal muscle in vivo. J. Clin. Invest. 89:1767-1744.

23. Nuutila, P., J. Knuuti, U. Ruotsalainen, V. A. Koivisto, E. Eronen, M Teräs, J. Bergman, M. Haaparanta, L.-M. Voipio-Pulkki, J. Viikari, T. Rönnema, U. Wegelius, and H. Yki-Järvinen. 1993. Insulin resistance is localized to skeletal but not heart muscle in type 1 diabetes. Am. J. Physiol. 264:E756E762.

24. DeFronzo, R. A., J. D. Tobin, and R. Andres. 1979. The glucose clamp technique: a method for quantifying insulin secretion and resistance. Am. J. Physiol. 237:E214-E223.

25. Yki-Järvinen, H., A. Consoli, N. Nurjhan, A. A. Young, and J. E. Gerich. 1989. Mechanism for underestimation of isotopically determined glucose disposal. Diabetes. 38:744-751.

26. Koivisto, V. A., H. Yki-Järvinen, I. Puhakainen, A. Virkamăki, J. Kolaczynski, and R. DeFronzo. 1990. No evidence for isotope discrimination of tritiated glucose tracers in measurements of glucose turnover in rates in man. Diabetologia. 33:168-173.

27. Kadish, A. H., R. L. Little, and J. C. Sternberg. 1968. A new and rapid method for the determination of glucose by measurement of rate of oxygen consumption. Clin. Chem. 14:116-131.

28. Gutman, I., and A. W. Wahlefeld. 1974. L-(+)-lactate determination with lactate dehydrogenase and NAD. In Methods of Enzymatic Analysis. H. U. Bergmeyer, editor. Academic Press, New York. Vol. 3:1964-1968.

29. Kuzuya, H., P. M. Blix, D. L. Horwitz, D. F. Steiner, and A. Rubenstein 1977. Determination of free and total insulin and C-peptide in insulin-treated diabetics. Diabetes. 26:22-29.

30. Miles, J., R. Glasscock, J. Aikens, J. Gerich, and M. Haymond. 1983. A microfluorometric method for the determination of free fatty acids in plasma. $J$. Lipid Res. 24:96-99.

31. Hamacher, K., H. H. Coenen, and G. Stöcklin. 1986. Efficient stereospecific synthesis of no-carrier-added $2-\left[{ }^{18} \mathrm{~F}\right]$-fluoro-2-deoxy-D-glucose using aminopolyether supported nucleophilic substitution. J. Nucl. Med. 27:235-238.

32. Spinks, T. J., T. Jones, M. C. Gilardi, J. D. Heatrec. 1988. Physical performance of the latest generation of commercial positron scanner. IEEE (Int. Electr. Electron. Eng.) Trancact. Nucl. Sci. 35:721-725.

33. Schelbert, H. R., E. Henze, H. R. Shon, R. Keen, H. Hansen, C. Selin, S.-C. Huang, J. R. Barrio, and M. Phelps. 1983. C-11 palmitate for the noninvasive evaluation of regional myocardial fatty acid metabolism with positron computed tomography. III. In vivo demonstration of the effects of substrate availability on myocardial metabolism. Am. Heart. J. 105:492-504.

34. Phelps, M. E., H. R. Schelbert, E. J. Hoffman, et al. 1980. Physiological tomography studies of myocardial glucose metabolism, perfusion nd blood pools with multiple gated acquisition. Adv. Clin. Cardiol. 1:373-393.

35. Huang, S.-C., M. Phelps, E. Hoffman, K. Sideris, C. Selin, and D. Kuhl. 1980. Noninvasive determination of local cerebral metabolic rate of glucose in man. Am. J. Physiol. 238:E69-E82.

36. Ratib, O., M. E. Phelphs, S. C. Huang, E. Henze, C. E. Selin, and H. R. Schelout. 1982. The deoxyglucose method for the estimation of basal myocardial glucose metabolism with positron computed tomography. J. Nucl. Med. 23:577586. 
37. Choi, Y., R. A. Hawkins, S.-C. Huang, S. S. Gambhir, R. C. Brunken, M. E. Phelps, and H. R. Schelbert. 1991. Parametric images of myocardial metabolic rate of glucose generated from dynamic cardiac PET and $2-\left({ }^{18} \mathrm{~F}\right)$ fluoro-2deoxy-d-glucose studies. J. Nucl. Med. 32:733-738.

38. Mossberg, K. A., R. W. Rowe, T. J. Tewson, and H. Taegtmeyer. 1989. Rabbit hindlimb glucose uptake assessed with positron-emitting fluorodeoxyglucose. J. Appl. Physiol. 67:1569-1577.

39. Durnin, J. V. G. A., and J. Womersley. 1974. Body fat assessed from total body density and its estimation from skinfold thickness: measurements on 481 men and women aged from 16-72 years. Br. J. Nutr. 32:77-97.

40. Yki-Jărvinen, H., and V. A. Koivisto. 1983. Effect of body composition on insulin sensitivity.

41. Sahn, D. J., A. DeMaria, J. Vasslo, and A. E. Weyman. 1978. Recommendations regarding quantitation of $\mathrm{M}$-mode echocardiography: results of a survey of echocardiographic measurements. Circulation. 58:1072-1077.

42. Grossman, W., D. Jones, and L. P. McLaurin. 1974. Wall stress and patterns of hypertrophy in the human left ventricle. J. Clin. Invest. 56:56-64.

43. Snedecor, G. W., and W. G. Cochran. 1967. Statistical Methods. 6th edition. Iowa State University Press, Ames. 59-76.

44. Soman, V. R., V. A. Koivisto, D. Deibert, P. Felig, and R. A. DeFronzo. 1979. Increased insulin sensitivity and insulin binding to monocytes after physical training. N. Engl. J. Med. 301:1200-1204.

45. Mikines, K. J., B. Sonne, P. A. Farrell, B. Tronier, H. Galbo. 1988. Effect of physical exercise on sensitivity and responsiveness to insulin in humans. Am.J. Physiol. 254:E248-E259.

46. Andersen, P., and J. Henriksson. 1977. Capillary supply of the quadriceps femoris muscle of man: adaptive response to exercise. J. Physiol. 270:677-690.

47. Taylor, A. W., R. Thayer, and S. Rao. 1972. Human skeletal muscle glycogen synthase activities with exercise and training. Can. J. Physiol. Pharma col. 50:411-415.

48. Ebeling, P., R. Bourey, L. Koranyi, J. A. Tuominen, L. C. Groop, J. Henriksson, M. Mueckler, A. Sovijärvi, and V. A. Koivisto. 1992. Mechanism of enhanced insulin sensitivity in athletes: increased blood flow, muscle glucose transport protein (GLUT-4) concentration and glycogen synthase activity. $J$. Clin. Invest. 1623-1631.

49. Leipänen, J. A., P. Virtanen, H. J. Ruskoaho, I. E. Hassinen, and T. E. S Takala. 1989. Transmural distribution of left ventricular glucose uptake in spon- taneously hypertensive rats during rest and exercise. Acta Physiol. Scand 135:435-442.

50. York, J. W., D. G. Penney, and L. B. Oscai. 1975. Effects of physical training on several glycolytic enzymes in the rat. Biochim. Biophys. Acta. 381:2227.

51. Morganroth, J., B. J. Maron, W. L. Henry, and S. E. Epstein. 1975 Comparative left ventricular dimensions in trained athletes. Annu. Int. Med. $82: 521-528$.

52. Osborne, G., L. A. Wolfe, G. W. Burgraf, and R. Norman. 1992. Relationship between cardiac dimensions, anthropometric characteristics and maximal aerobic power ( $\mathrm{VO}_{2} \max$ ) in young men. Int. J. Sports Med. 13:219-224.

53. Randle, P. J., P. B. Garland, C. N. Hales, and E. A. Newsholme. 1963. The glucose fatty acid cycle: its role in insulin sensitivity and the metabolic disturbances of diabetes mellitus. Lancet. 785-789.

54. Nuutila, P., M. J. Knuuti, U. Ruotsalainen, M. Teräs, L.-M. VoipioPulkki, M. Haaparanta, J. Bergman, and H. Yki-Järvinen. 1993. Differences in the regulation of glucose uptake by free fatty acids in heart and skeletal muscle in man. Diabetologia. 36(Suppl 1):A54.

55. van der Vusse, G. J., and M. J. M. de Groot. 1992. Interrelationship between lactate and cardiac fatty acid metabolism. Mol. Cell. Biochem. 116:1117.

56. De Groot, M. J. M., P. H. M. Willemsen, W. A. Coumans, M. van Bilsen, and G. J. van der Vusse. 1989. Lactate-induced stimulation of myocardial triacylglycerol turnover. Biochim. Biophys. Acta 1006:111-115.

57. Ferre, P., A. Leturque, A.-F. Burnol, L. Penicaud, and J. Girard. 1985. A method to quantify glucose utilization in vivo in skeletal muscle and white adipose tissue of the anesthetized rat. Biochem. J. 228:103-110.

58. Meszaros, K., G. J. Bagby, C. H. Lang, and J. J. Spitzer. 1987. Increased uptake and phosphorylation of 2-deoxyglucose by skeletal muscles in endotoxin treated rats. Am. J. Physiol. 253:E33-E39.

59. Burnol, A.-F., P. Ferre, A. Leturque, and J. Girard. 1987. Effect of insulin on in vivo glucose utilization in individual tissues of anesthetized lactating rats. Am. J. Physiol. 252:E183-E188.

60. Park, J. H., R. L. Brown, C. R. Park, M. Cohn, and B. Chance. 1988. Energy metabolism of the untrained muscle of elite runners as observed by ${ }^{31} \mathrm{P}$ magnetic resonance spectroscopy: evidence suggesting a genetic endowment for endurance exercise. Proc. Natl. Acad. Sci. USA. 85:8780-8784. 